\title{
INTERVIEW
}

\section{MIND, BODY AND WORLD IN THE PHILOSOPHY OF HILARY PUTNAM}

\author{
Dr. Hilary Putnam (Harvard University) ${ }^{I}$
}

\section{Dr. Léo Peruzzo (Pontifícia Universidade Católica do Paraná) ${ }^{2}$}

1. Léo Peruzzo - Dear professor Putnam, your philosophical career was marked at the beginning by the influence of logical positivism, especially by Carnap. However, as we know, logical positivism argues (in addition to arguing for the unification of the language of science) that scientific theories can describe the "reality". I believe that since the 1960s you have supported a kind of "realism" according to which scientific theories are approximately true. In what sense must we understand, therefore, the task of scientific theories? Could they arrive, at some time in history, to the "reality"?

Hilary Putnam - Forgive me for correcting your history of positivism, but if I don't do that what I go on to say won't be intelligible! Your description of positivism fits the nineteenth century "positivism" of Auguste Comte, which is well known in Brazil (and deserves more attention from historians of the philosophy of science in other countries than it has received in recent years), but it does not fit logical positivism at all. For Carnap, "reality" was

${ }^{1}$ Cogan University Professor Emeritus in the Department of Philosophy at Harvard University. Hilary W. Putnam was born in Chicago in 1926. He received his PhD in 1951 from UCLA, where he worked with Hans Reichenbach. Before joining the faculty of Harvard in 1965, he taught at Northwestern University (1951-2), Princeton University (1953-61), where he received tenure in both the Department of Philosophy and the Department of Mathematics in 1960, and after that at M.I.T. (1961-65). He is a past President of the American Philosophical Association (Eastern Division), the Philosophy of Science Association, and the Association for Symbolic Logic. He is a Fellow of the American Academy of Arts and Sciences, the American Philosophical Society, a Corresponding Fellow of the British Academy and the French Academie des Sciences Politiques et Morales, and holds a number of honorary degrees. He has received the Prometheus Prize of the American Philosophical Association and the Rolf Schock Prize in Philosophy.

${ }^{2}$ Professor at Pontifícia Universidade Católica do Paraná - PUCPR. E-mail: leo.junior@pucpr.br 
a meaningless metaphysical concept, or rather pseudo-concept. His favorite examples of "pseudo-problems" (Scheinprobleme) were questions of the form "Are so-and-sos real?", e.g. "Are electrons real?", "Are numbers and other mathematical objects real?". "Scientific theories can describe the 'reality" is a sentence he would have regarded as meaningless (Sinnlos).

Thus, in the first published lecture in which I attacked the logical positivist view of theories, "What Theories Are Not" (1960), I was breaking with logical positivism, not agreeing with it, when I advocated "a rather minimal scientific realism". What I meant by that expression was a realism according to which terms like "charge" and "mass" cannot be and do not need to be explained using only Carnap's so-called "observation terms", but refer to real physical magnitudes

With regard to the questions as to whether scientific theories could eventually "arrive at the reality", I think in part they already do "arrive at reality". Water molecules consist of oxygen and hydrogen (plus a small percentage of deuterium, an isotope of hydrogen), and that statement, we have excellent reason to think, is simply true. But exactly how atoms behave is something we will only know when (and if) we ever have a theory that explains how present day quantum mechanics and present day relativity theory can both be approximately true. Can we arrive at such a theory "some time in history"? We don't know, but there is no justification I know of for saying it is impossible.

2. Léo Peruzzo - The success of the mature sciences is in the fact that they best approach "truth" and indicate appropriate justifications for the understanding of reality. In what sense do you believe that this vision eliminates the metaphysical biases? Are there metaphysical problems that would be important for the activity of science? Would it be necessary to flee the metaphysics to think of the progress of science?

Hilary Putnam - I reject the idea that metaphysics can be done independently of science. I also reject the idea that science can just ignore such "metaphysical" questions as the reality of theoretical entities. The positivist idea that all science does is to predict the observable results of experiments is still popular with some scientists, but it always leads to the evasion of important foundational questions. For example, the recognition that there is a problem of understanding quantum mechanics, that is, a problem of figuring out just how physical reality must be in order for our most fundamental physical theory to work as successfully as it does, is becoming more widespread, but that 
recognition was delayed for decades by the claim that something called "The Copenhagen Interpretation" of Niels Bohr had solved all the problems. Yet the "Copenhagen interpretation," in Bohr's version, amounted only to the vague philosophical thesis that the human mind couldn't possibly understand how the quantum universe was in itself, and should just confine itself to telling us how to use quantum mechanics to make predictions!

3. Léo Peruzzo - In an interview conducted in 2010, you said that if you were to write another $\mathrm{PhD}$ dissertation it would be in philosophy of mind, more specifically on the issue of perception. As I think of this same problem, how do you see, then, the relationship between the perception and the mental contents integrating the liberal functionalist theory?

Hilary Putnam - I am currently working on papers and a book defending and developing a liberal functionalist view of perception, apperception and consciousness. By a "liberal functionalist view" I mean a view according to which mentality is a collection of interrelated world-involving abilities. The brain may be, among other things, a computer, but the mind is more than the brain, according to liberal functionalism. According to the anti-individualist and externalist view I defend, the mind cannot be described without describing the transactions of the organism with an environment, including, in the human case, the social environment. Liberal functionalist is not reductionist; as I once put it, "explanations seek their own level". (Like Aristotle, I think that things have many levels of form.)

I will say something about perception when we come to question 6 .

4. Léo Peruzzo - It is well-known that your theory in philosophy of mind adopts a realistic position. However, it denies that mental states can be reduced to physical states, or the brain. In principle, would not thinking the mental contents by means of functional processes resurrect some sort of metaphysical explanation? What is the best image to think about what the "mind" is?

Hilary Putnam - Of course the view that mental states are ways of functioning is a metaphysical view. But it is also a scientific or proposed scientific picture. I don't believe that metaphysics is "first philosophy"; metaphysics and science have to interact, and be done simultaneously. And yes, I no longer believe that the computer is the best image to think about the mind.

5. Léo Peruzzo - Thinking, then, specifically in functionalist theory, could we say that in the near future machines, robots and cyborgs will have the 
same capacities as humans, and that artificial intelligence will be an amazing mystery? Currently, could the experiment of the "brain in a vat" tell us what kind of limitations there are to these issues?

Hilary Putnam - You are thinking of "computational state functionalism", my position in the 1960s and 1970s. Liberal functionalism has no commitments one way or the other on the possibility and/or limits of artificial intelligence. Time will tell.

6. Léo Peruzzo - The qualia include feelings or phenomenological aspects of the experience, such as the sensation of itch produced by a blanket, the fear caused by a horror film, or the admiration of a valley covered with flowers under the strong sun of summer. The qualia, it is assumed, are subjective and private to the person, and there are, in addition to public events, physical events that occur in the brain of someone. In this respect, how can we resolve the famous problem of "other minds"? If we have the same perception of the object, why do we have different answers? Is it a fault in a relativistic response that one never knows what is happening in the minds of others?

Hilary Putnam - Much traditional philosophy (with Kant being the great exception) assumes that to have qualia is ipso facto to perceive something. I think this is the great mistake of empiricism. In my view, qualia are not perceptions. Even for animals, perception does not begin with qualia (insects perceive, but who knows if they have qualia?), but with perceptual representation (note that representation is neither a phenomenological notion nor a physicalist one, but it is the subject of a lot of sophisticated psychological research, regardless of whether it fits into philosophers' pet categories (such as "mental", "physical", "intentional"). This is the moral of Tyler Burge's wonderful book Origins of Objectivity. In the case of humans, it is not perceptual representations that enter into knowledge, although they are the "ground level", so to speak, but apperceptions (to use Kant's term). When I apperceive a delicious cup of coffee on the table, my apperception is (what I called before) a world involving transaction between me and the cup of coffee. I may or may not pay any attention to my qualia, in fact: I see the cup.

As for the problem of other minds, I think we are built to know what goes on in others' minds (think of mirror neurons in the brain). The skeptic says this begs the question. So what? Why should we suppose that we can give the skeptic an answer that the skeptic himself must accept? Too much ink has been spilled on that futile project. 
7. Léo Peruzzo - I would like, now, to turn to a classical question in your "semantic externalism". You understand that this position is an "antisubjectivist revolution" in philosophy. What can we understand by this argument?

Hilary Putnam - I urge your readers to read my "The Meaning of 'Meaning". I can't summarize the argument in the space of an interview. But the gist is that our words don't have meanings just by going through our heads; only as a being related to a world and to other people in certain ways do we have thoughts with content at all. This is the heart of my "semantic externalism".

8. Léo Peruzzo - Your neopragmatist vision particularly rejects "scientism" and is derived from, to a large extent, by the reading of James and the pluralistic view of the writings of Wittgenstein. Especially in Pragmatism: An Open Question, you expressed that the major philosophical problems are conceptual or linguistic confusions. To what extent, therefore, would neopragmatism continue being an interesting vision?

Hilary Putnam - I think that that phase in my thinking (particularly Pragmatism: An Open Question) was too much influenced by Wittgenstein. I draw back from much of that in "Wittgenstein: A Reappraisal" (in my Philosophy in an Age of Science). Of course philosophers make mistakes and there are confusions in philosophy, but they are not, in most cases, linguistic confusions, as Wittgenstein thought. As for James and the Pragmatists, I like their holistic view of inquiry, and their rejection of the fact/value dichotomy, but I have never subscribed to their theory (or theories) of truth. Still, one can learn much from James and Dewey.

9. Léo Peruzzo - Inevitably (and fortunately), philosophical activity is in the era of science, that is to say, the events of the globalization of knowledge. How do you analyze the ethical, political, religious and social issues in the contemporary setting? Can we answer the question: where is humanity going?

Hilary Putnam - I have no "sound bites" here. (I am a left-social democrat, albeit a pessimistic one at the moment.) Feeding the hungry, clothing those who are in rags, opposing injustice and oppression, providing a place for refugees from persecution and starvation-all this while also defending freedom of speech and thought, including freedom for artistic expressionare the most important things we need to do. 
10. Léo Peruzzo - Your work and thoughts have influenced a hundred Brazilian philosophers, especially with regard to a realistic posture facing the epistemological problems of language and mind. How do you analyze your work today? And how do you see the direction of philosophy in general?

Hilary Putnam - I began my philosophical career as a philosopher of science, although already in the introduction to my first collection of papers I wrote that philosophy of science is not all of philosophy. It was the fact that at that time (the 1960s and the beginning of the 1970s) leading philosophers of science were still committed to the identification of meaningfulness with having something they called a "method of verification" that led me to show that logical positivism was wrong both as a description of science and as a theory of meaning, and that led me from philosophy of science into philosophy of language and to the anti-subjectivist semantic externalism that you asked about. Because I was also active in mathematical logic and computer science, I was led to functionalism, and more recently, perceiving that my original version of functionalism was too reductionist, to "liberal functionalism". I was also long convinced that the positivists' fact/value dichotomy was untenable, both as a description of what facts are and as a description of what values are, and my admiration for Amartya Sen's approach to economics, an approach that obviously rejects that dichotomy, inspired me (in The Collapse of the Fact/ Value Dichotomy) to propose an account of ethics that in many ways supports Sen's "human capabilities approach" to economics. I view my work as an encouragement to those who see philosophy not as a collection of "problems" that can be "solved" one by one, but as a great humanistic and scientific enterprise, the enterprise of seeking a view of reality that is simultaneously realistic and humane, both intellectual and practical. I hope that is how philosophers will see our field in the future, but I have no crystal ball.

Recebido / Received: 10/03/2015 